\title{
A study in a teritary centre for clinical assessment of pelvic inflammatory disease risk among women attending outpatient department
}

\author{
Sowmya D. ${ }^{1}$, Sowjanya D. ${ }^{2 *}$
}

\begin{abstract}
${ }^{1}$ Department of Obstetrics and Gynecology, SMS Medical College, Jaipur, Rajasthan, India
${ }^{2}$ Department of Community Medicine, Vydehi Institute of Medical Sciences and Research Centre, Bangalore, Karnataka, India
\end{abstract}

Received: 19 July 2017

Accepted: 24 July 2017

\section{*Correspondence: \\ Dr. Sowjanya D., \\ E-mail: sowjanyad6@gmail.com}

Copyright: (c) the author(s), publisher and licensee Medip Academy. This is an open-access article distributed under the terms of the Creative Commons Attribution Non-Commercial License, which permits unrestricted non-commercial use, distribution, and reproduction in any medium, provided the original work is properly cited.

\section{ABSTRACT}

Background: Pelvic inflammatory disease (PID) is associated with major medical and economic consequences for women of reproductive age. Identification of the risk factors associated with PID is crucial to efforts for prevention of these consequences. This study is done to evaluate the risk factors for PID in women attending OPD at Gangori hospital.

Methods: This Study is an observational study, Conducted in Department of Obstetrics and Gynecology, Gangori hospital, SMS Medical College, Jaipur, From January 2015 to June 2015. Risk factors of PID were assessed in 70 women with PID (study group) and then it was compared with 70 controls attending the Women's Clinic at the same institution. Significance of difference in proportion in various variables of PID in both the group was inferred by odd's ratio and Chi-square test. Logistic regression analysis was used to adjust for confounding variables.

Results: A total of 70 women with PID and an equal number of controls were included. Cases were significantly younger than controls $(\mathrm{p}<0.001)$. The women were mainly of lower socioeconomic status. Risk factors identified by bivariate analysis were less than secondary level education, Odds ratio [OR] 5.29; (95\% confidence interval: 1.680 to 16.675) $\mathrm{P}$ value 0.005 . Parity $>0$, Odds ratio 2.521 (95\% CI: 1.140 to 5.577) $\mathrm{P}$ value 0.033 . Spontaneous abortion $>0$, Odds ratio 3.11 (95\% CI: 1.311 to 7.362$) \mathrm{P}$ value 0.015 . Lack of a birth control method, Odds ratio 7.18 (95\% confidence interval: 3.091 to 16.662) p value<0.001. younger than 18 years at age of first sex, Odds ratio 2.84 (95\% CI: 1.404 to 5.753) P value 0.006. Sex during the previous menses Odds ratio 5.39 (95\% CI: 2.317 to 12.529) $\mathrm{P}$ value $<0.001$. Vaginal discharge/bleeding, Odds ratio 5.84 (confidence interval 2.717 to 12.578 ) $\mathrm{P}$ value $<0.001$. With multivariate analysis to control for confounders the risks still identified were sex during the previous menses, parity $>0$, lack of contraception, vaginal discharge and age at first sex.

Conclusions: Identification of the risk factors associated with PID is most important effort for prevention of the disease and its sequelae. Educating the women, encouraging the use of condoms and other methods of contraception for PID prevention, sexually transmitted disease prevention and also birth control. Another finding is that, it is better to avoid coitus during the menses.

Keywords: Contraception, PID, Risk factor, Sexually transmitted disease 


\section{INTRODUCTION}

Infections of the upper genital tract include infections involving the endometrium, myometrium, fallopian tubes, ovaries, uterine serosa, broad ligaments and pelvic peritoneum. Pelvic inflammatory disease (PID) is an important health problem with serious repercussion on women's health and well-being. Other than the chronicity of lower abdominal pain marring the women's wellbeing, infertility and its associated stigma compounds the need to study this issue in developing country like India. Pelvic inflammatory disease (PID) is varied clinical presentation of polymicrobial infection, it is the disease with multiple, interrelated risks, education is one of the most important nursing intervention. PID has emerged as a silent killer that disturbs women's life, the disease if left untreated could result in serious complications (Pandey $\mathrm{S}$ et al). ${ }^{1}$ It is also associated with major medical and economic consequences of sexually transmitted disease in women of reproductive age. PID is an important disease not only because of its acute morbidity but because of its sequeale among women of reproductive age (Jossens et al). ${ }^{2}$ It is one of the most serious infections faced by todays women.

\section{Etiology}

PID is caused by organisms ascending from the endocervix and vagina and therefore a polymicrobial infection. A practical approach to diagnosis of PID by Oluwatosin et al are lower genital inflammation and pelvic organ tenderness in women with genital tract symptoms and risk of STI's. ${ }^{3}$ In the absence of laparoscopy, the triad of lower abdominal pain, cervical motion tenderness, and bilateral adnexal tenderness has been advocated as the minimal criterion for clinical diagnosis of PID, Eschenbach et al. ${ }^{4}$ Diagnosing PID on purely clinical grounds is often difficult and the margin for error is wide. In this context, knowledge of risk factors like young age, low socioeconomic status, multiple sex partners and markers for PID could substantially aid diagnosis. Additional criteria for diagnosis PID oral temperature $>38.3 \mathrm{c}$, mucopurulent cervical and vaginal discharge, raised c- reactive protein or ESR, Laboratory documentation of positive cervical infection. The true prevalance of PID is unknown, accurate diagnostic procedures for the disease complex, interpretation of symptoms and signs can vary by clinicians, clinical settings and by the period, Greenberg et al $1992 .{ }^{5}$

\section{Complications of PID}

Immediate: pelvic peritonitis or even generalized peritonitis, septicemia. Late: dyspareunia, chronic pelvic inflammation, formation of adhesions or hydrosalpinx or pyosalpinx and tubovarian abscess, tubal damage leading to infertility, increased risk of ectopic pregnancy. Protective factors are barrier methods of contraceptive, monogamy, others are pregnancy, menopause, HPV vaccines.

Centers for disease control and prevention (CDC) recommends treatment of PID initiated in sexually active young women, especially those risk for STI's with pelvic or lower abdominal pain, if no other causes other than PID can be identified i.e cervicitis or leukorrhoea and any pelvic organ tenderness on bimanual examination, (Oluwatosin et al). ${ }^{3}$ Outpatient treatment of PID ceftriaxone $250 \mathrm{mg}$ IM single dose, doxycycline $100 \mathrm{mg}$ per oral twice daily for 14 days with or without metronidazole $500 \mathrm{mg}$ per oral twice daily for 14 days or cefoxitin $2 \mathrm{~g}$ IM single dose and probenecid $1 \mathrm{~g}$ plus doxycycline $100 \mathrm{mg}$ twice for 14 days with or without metronidazole $500 \mathrm{mg}$ twice daily for 14 days. All patients treated in the outpatients are evaluated after 48 hours and if no response is to be hospitalized. In patient antibiotic therapy, cefotetan $2 \mathrm{~g}$ iv every 12 hours plus doxycycline $100 \mathrm{mg}$ orally or iv every 12 hours, or cefoxitin $2 \mathrm{~g}$ IV every 6 hours plus doxycycline $100 \mathrm{mg}$ IV or orally every 12 hours or another Regimen clindamycin $900 \mathrm{mg}$ iv every 8 hours, gentamycin loading dose $2 \mathrm{mg} /$ day followed by a maintenance dose of $1.5 \mathrm{mg}$ /day every 8 hours. Alternative regimen Ampicillin sulbactum $3 \mathrm{gm}$ iv for every 6 hours plus doxycycline $100 \mathrm{mg}$ iv or orally every 12 hours. Having the knowledge of risk factors of PID, Appropriate diagnosis and simple approach may prevent long term sequeale.

This study was conducted to assess sexual, social, and demographic risk factors for the acquisition of PID, diagnosed presumptively in women attending a health service and on the basis of these findings to formulate health promotion recommendations to reduce the incidence and consequences of PID. Identification of the risk factors associated with PID is crucial to efforts for prevention of these consequences.

\section{METHODS}

This Study is a Hospital based, observational study, Conducted in Department of Obstetrics and Gynecology, Gangori hospital, SMS Medical College Jaipur, From January 2015 to June 2015 total of 6 months. After consenting sexually active women those meeting the diagnostic criteria of PID, seventy women with PID (cases) were taken as study group and for each case, control was selected from women attending hospital for other complaints, at the same institution (controls). They were interviewed for 30 minutes. Patient having Abdominal pain due to kidney/liver/gall bladder disease and those Patient who has undergone recent abdominal surgery, pregnancy/lactating women, were excluded from the study.

\section{Statistical analysis}

Study analysis was done using odd's ratio, Chi-square test and Logistic regression analysis. 


\section{RESULTS}

A Total of 140 women (70 in each group) were observed. Mean age of the patients at the time of observation $26.99 \pm 4.03$ years. (Case 26.64 \pm 4.1 and control $27.33 \pm 3.9, \mathrm{P}$ value $>0.05 \mathrm{NS}$ ) (Table 1$)$.

Table 1: Mean age wise distribution.

\begin{tabular}{|llll|l|}
\hline Age & N & Mean & Std. deviation & P value \\
\hline Case & 70 & 26.64 & 4.104 & \\
\hline Control & 70 & 27.33 & 3.963 & $>0.05$ \\
\hline Total & 140 & 26.79 & 4.618 & NS $^{*}$ \\
\hline
\end{tabular}

$\mathrm{NS}^{*}=$ not significant

In present study, cases are more from urban population $64.3 \%$ and with lower socioeconomic status which is $71.4 \%$ and patients with education level less than 10th standard which accounts to $94.2 \%$ (Table 2).

Table 2: Demographic profile of study population.

\begin{tabular}{|lllll|}
\hline Variables & \multicolumn{2}{c|}{ Cases $(\mathbf{N}=70)$} & \multicolumn{2}{c|}{ Control $(\mathbf{N}=70)$} \\
\hline Ho & \% & No & $\%$ \\
\hline Urindu & 53 & 75.7 & 58 & 82.9 \\
\hline $\begin{array}{l}\text { Lower } \\
\text { socioeconomic } \\
\text { status }\end{array}$ & 45 & 64.3 & 36 & 51.4 \\
\hline $\begin{array}{l}\text { Education less } \\
\text { than } 10^{\text {th }} \text { class }\end{array}$ & 66 & 71.4 & 46 & 65.7 \\
\hline
\end{tabular}

Table 3: Analysis of risk factors.

\begin{tabular}{|c|c|c|c|c|c|c|}
\hline Variables & Case $(\mathrm{N}=70)$ & Control $(\mathrm{N}=70)$ & OR & $95 \%$ confidence interval & P value & Significance \\
\hline \multicolumn{7}{|l|}{ Education } \\
\hline Less than secondary & 66 & 53 & \multirow{2}{*}{5.29} & \multirow{2}{*}{1.680 to 16.675} & \multirow{2}{*}{0.005} & \multirow{2}{*}{ HS* } \\
\hline More than secondary & 4 & 17 & & & & \\
\hline \multicolumn{7}{|l|}{ Parity } \\
\hline$>0$ & 58 & 46 & \multirow{2}{*}{2.52} & \multirow{2}{*}{1.140 to 5.577} & \multirow{2}{*}{0.033} & \multirow{2}{*}{$\mathrm{S}^{*}$} \\
\hline 0 & 12 & 24 & & & & \\
\hline \multicolumn{7}{|l|}{ Spontaneous abortion } \\
\hline 1 & 61 & 48 & \multirow{2}{*}{3.11} & \multirow{2}{*}{1.311 to 7.362} & \multirow{2}{*}{0.015} & \multirow{2}{*}{$\mathrm{S}^{*}$} \\
\hline 0 & 9 & 22 & & & & \\
\hline \multicolumn{7}{|l|}{ Contraception use } \\
\hline $\begin{array}{l}\text { Lack of contraception } \\
\text { use }\end{array}$ & 36 & 9 & \multirow[t]{2}{*}{7.18} & \multirow[t]{2}{*}{3.091 to 16.662} & \multirow[t]{2}{*}{$<0.001$} & \multirow[t]{2}{*}{ HS* } \\
\hline Contraception use & 34 & 61 & & & & \\
\hline \multicolumn{7}{|l|}{ Sex during menses } \\
\hline Yes & 31 & 9 & \multirow{2}{*}{5.3} & \multirow{2}{*}{2.317 to 12.529} & \multirow{2}{*}{$<0.001$} & \multirow{2}{*}{ HS* } \\
\hline No & 39 & 61 & & & & \\
\hline \multicolumn{7}{|l|}{ Age at first coitus } \\
\hline Yes & 36 & 19 & \multirow{2}{*}{2.84} & \multirow{2}{*}{1.404 to 5.753} & \multirow{2}{*}{0.006} & \multirow{2}{*}{$\mathrm{S}^{*}$} \\
\hline No & 34 & 51 & & & & \\
\hline \multicolumn{7}{|c|}{ Vaginal discharge/bleeding } \\
\hline Yes & 40 & 13 & \multirow[t]{2}{*}{5.84} & \multirow[t]{2}{*}{2.717 to 12.578} & \multirow[t]{2}{*}{$<0.001$} & \multirow[t]{2}{*}{$\mathrm{S}^{*}$} \\
\hline No & 30 & 57 & & & & \\
\hline
\end{tabular}

HS $*$ Highly Significant; S $^{*}=$ Significant
In present study, maximum number of cases are from the younger age group that is 20 to 24 years as shown in Figure 1.

Subjects who studied less than 10 standard, Odds ratio was (OR) 5.29; (95\% confidence interval: 1.680 to 16.675) with $\mathrm{P}$ value 0.005 , found to be highly significant, that is women with less education are with more risk for PID compare to education above 10 standards. Parity >0, Odds ratio was 2.521 (95\% CI: 1.140 to 5.577 ) with $\mathrm{P}$ value 0.033 which is statistically significant, suggests greater the parity, greater risk for PID. Spontaneous abortion $>0$, Odds ratio was $3.11(95 \%$ CI: 1.311 to 7.362 ) with $\mathrm{P}$ value 0.015 is statistically significant, more number of abortion increases PID risk proportionally.

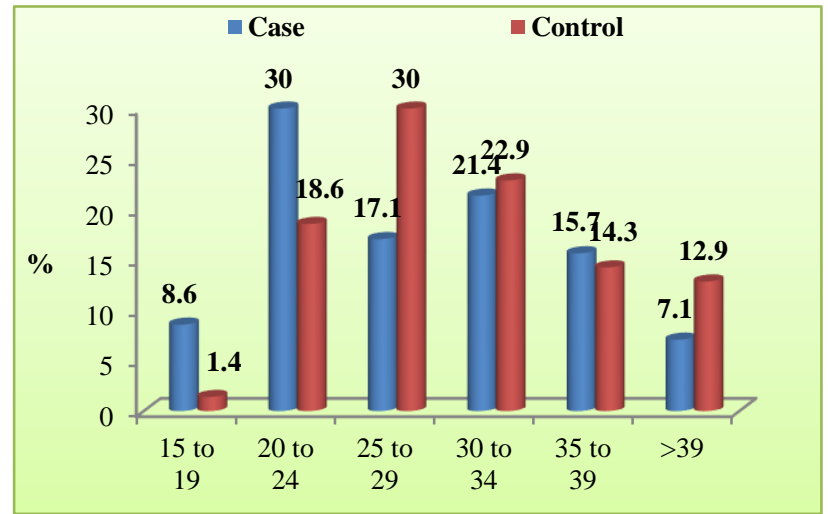

Figure 1: Age wise distribution of cases. 
Lack of a birth control method variant, Odds ratio was 7.18 (95\% confidence interval: 3.091 to 16.662 ) with $\mathrm{p}$ value $<0.001$, found to be highly significant. It suggests women who does not use contraception are in risk with PID compare to women who uses contraception. Younger than 18 years at the age of first coitus act, Odds ratio 2.84 (95\% CI: 1.404 to 5.753) with P value 0.006, significant. It shows Coitus at younger age is also a risk factor for PID.

Sex during the previous menses, Odds ratio $5.39(95 \%$ CI: 2.317 to 12.529 ) with $\mathrm{P}$ value $<0.001$, significant. That is coitus during menses is a risk for developing PID. Vaginal discharge/bleeding, Odds ratio 5.84 (confidence interval 2.717 to 12.578$) \mathrm{P}$ value $<0.001$, significant. That is women who have vaginal discharge/bleeding are in risk with PID (Table 3).

\section{DISCUSSION}

In present study, Clinical assessment of risk for pelvic inflammatory disease among women attending outpatient are analysed, 140 women (70 in each group) were observed, mean age of cases are 26.64 year and controls are 27.33 year (Table 1). whereas study in Leichliter et al mean age of case was 31.4 year and control was 27.2 year. ${ }^{6}$ Study by Simms I et al opined diagnosis of PID were made at $1.7 \%$ of attendances amongst women aged 16 to 46 years and also increased risk was with younger age groups and Lower socioeconomic status, which is similar to our study, $30 \%$ of cases are from 20 to 24years. ${ }^{7}$ A study by Marks $\mathrm{C}$ et al showed cases are significantly younger than controls. ${ }^{8}$

In present study cases of Pelvic inflammatory disease are more from urban population 45 (64.3\%), lower socio economic status $50(71.4 \%)$, education less than $10^{\text {th }}$ class are $66(94.28 \%)$ Table 2, which is similar to study by Jossens et al on average patients had fewer years of education than controls and says education is important nursing intervention. ${ }^{2}$ Also a study done by Heather G Miller et al titled correlates of sexually transmitted bacterial infections among US women in 1995. ${ }^{9}$ Education, age, intra uterine device use, history of bacterial STD's had a significant impact on risk of PID and also said $17 \%$ sexual active women with STD's had education less than secondary.

Risk factor for PID markers in our study are education less than ten standard, parity $>0$, spontaneous abortion $>0$, lack of birth control method, less than 18 year at the age of first coitus, coitus during previous menses and women with vaginal discharge/bleeding, which is similar to study of Jossens et al, named risk factors of pelvic inflammatory disease case control study. ${ }^{2}$ In present study sex during menses is most important risk factor for PID with odds ratio of 5.39 (95\% CI: 2.317 to 12.529$) \mathrm{P}$ value $<0.001$. which is similar to study by Eschenbach et al, patients with PID were more likely than controls who avoided coitus during menses and also in present study it is found that lack of contraceptive method carries a risk of PID (odds ratio 7.18 confidence interval of 1.3 TO 7.3) $\mathrm{p}$ value 0.015 which is similar to study by Marks $\mathrm{C}$ et al not using contraception (OR 1.8) 95\% confidence interval 1.20 to 2.76 was associated with increased risk of PID. ${ }^{4,8}$ Jossens et al study opines, use of barrier methods may not only reduces the risk of PID but also transmission of HIV. $^{2}$

Less than 18 years at the age of first coitus, Odds ratio 2.84 (95\% CI: 1.404 to 5.753 ) $\mathrm{P}$ value 0.006 . coitus at younger age is also a significant risk factor for PID in our study, which is corresponding to study by Greenberg $\mathbf{J}$ et al, age at first coitus marker for risky sexual behavior in women. ${ }^{5}$

In another study by Miller HG et al indicates the risk factors associated with a history of PID are similar to those associated with bacterial infection, women who had first intercourse before 15 were twice as likely to have PID as were those who had first intercourse after age $18 .{ }^{9}$ Logistic regression results showing women likelihood of having had a bacterial STD's or having received PID treatment. Overall $6 \%$ of sexually active women reported a history of a bacterial STD's and $8 \%$ reported a history of PID.

In present study spontaneous abortion $>0$, Odds ratio 3.11 (95\% CI: 1.311 to 7.362 ) $\mathrm{P}$ value 0.015 is significant, abortion increases PID risk and abortions are predisposing factor for PID. Which is similar to study by Patel SV et al, where the odd ratio for PID with natural abortions as a risk factor was 3.52. ${ }^{10}$ Another study by Dalaker et al it was noticed that overall rate of PID after the abortion was $4.1 \% .^{11}$ Study by Gogate et al says, among women presenting to clinics in mumbai, India for pelvic pain and it was found that $26 \%$ with confirmed PID reported to have undergone abortion as compared to $2 \%$ of women without PID. ${ }^{12}$

In present study after applying multivariate analysis to control for confounders the risks still identified were sex during the previous menses (odds ratio 12.715) $\mathrm{p}$ value 0.000 , parity $>0$ (odds ratio 7.55 ) $\mathrm{p}$ value 0.001 , lack of contraception (odds ratio.166) $\mathrm{p}$ value 0.000 and vaginal discharge (odds ratio11.082) $\mathrm{p}$ value 0.00 , but age at first sex and abortion were consider as non-significant risk factor. Compared to study Jossen et al variables remained significant risk factors for PID are parity $>0$ (odds ratio 4.44), sex during the previous menses (odds ratio 5.22), lack of contraception (odds ratio7.66) were risk for PID. ${ }^{2}$

This study is limited to one medical school finding with smaller population. Large number of studies with different population are required.

\section{CONCLUSION}

Identification of the risk factors associated with Pelvic inflammatory disease is most important effort for 
prevention of the disease and its sequelae. Educating the women, encouraging the use of condoms and other methods of contraception for PID prevention, sexually transmitted disease prevention and also birth control. Another finding is that, it is better to avoid coitus during the menses.

Funding: No funding sources Conflict of interest: None declared

Ethical approval: The study was approved by the Institutional Ethics Committee

\section{REFERENCES}

1. Pandey S, Pandey R. Correlation of PID and multiparity: a case control study. Int J Reprod Contracept Obstet Gynecol. 2017;6(3):897-900.

2. Jossens MO, Eskenazi B, Schachter J, Sweet RL. Risk factors for pelvic inflammatory disease. A case control study. Sex Transm Dis. 1996;23(3):239-47.

3. Jaiyeoba O, Soper DE. A practical approach to the diagnosis of pelvic inflammatory disease. Infect Dis Obstetrics Gynecol. 2011;2011.

4. Eschenbach DA, Harnisch JP, Holmes KK. Pathogenesis of acute pelvic inflammatory disease: Role of contraception and other risk factors. Am J Obstet Gynecol. 1977;128:838-50.

5. Greenberg J, Magder L, Aral S. Sex age at first coitus. A marker for risky sexual behavior in women. Transm Dis. 1992;19(6):331-4.

6. Leichliter JS, Chandra A, Aral SO. Correlates of self-reported pelvic inflammatory disease treatment in sexually experienced reproductive-aged women in the United States, 1995 and 2006-2010. Sex Transm Dis. 2013;40(5):413-8.

7. Simms I, Vickers MR, Stephenson J, Rogers PA, Nicoll A. National assessment of PID diagnosis, treatment and management in general practice: England and Wales. Int J STD AIDS. 2000;11:440-4.

8. Marks C, Tideman RL, Estcourt CS, Berry G, Mindel A. Assessment of risk for pelvic inflammatory disease in an urban sexual health population. Sex Transm Infect. 2000;76:470-3.

9. Miller HG, Cain VS, Rogers SM, Gribble JN, Turner CF. Correlates of sexually transmitted bacterial infections among US women in 1995. Fam Plann Perspect. 1999:4-23.

10. Patel S, Baxi R, Kotecha P, Mazumdar V, Mehta K, Diwanji M. Association between pelvic inflammatory disease and abortion. Indian J Sex Transm Dis. 2010;31(2):127-8.

11. Dalaker K, Sundfør K, Skuland J. Early complications of induced abortion in primigravidae. Ann Chir Gynecol. 1981;70(6):331-6.

12. Gogate A, Brabin L, Nicholas S, Gogate S, Gaonkar T, Naidu A et al. Risk factors for laparoscopically confirmed pelvic inflammatory disease: findings from Mumbai (Bombay), India. Sex Transm Infect. 1998;74(6):426-32.

Cite this article as: Sowmya D, Sowjanya D. A study in a teritary centre for clinical assessment of pelvic inflammatory disease risk among women attending outpatient department. Int J Reprod Contracept Obstet Gynecol 2017;6:3823-7. 